\title{
The role of FRP composites in a sustainable world
}

\author{
Luke S. Lee · Ravi Jain
}

Published online: 12 August 2009

(C) Springer-Verlag 2009

Use of fiber reinforced polymer (FRP) composites for construction of new structures and rehabilitation of existing structures has increased significantly over past decades. FRP composites are lightweight, noncorrosive, exhibit high specific strength, and specific stiffness, are easily constructed, and can be tailored to satisfy performance requirements. For structural applications, FRP composites are typically fabricated using a polymer matrix, such as epoxy, vinylester, or polyester, and reinforced with various grades of carbon, glass, and/or aramid fibers. Due to its advantageous characteristics, FRP composites have been included in new construction and rehabilitation of structures through its use as reinforcement in concrete, bridge decks, modular structures, formwork, and external reinforcement for strengthening and seismic upgrade. While the mechanical advantages of using FRP composites are widely reported in literature, questions remain in regards to the feasibility of FRP composites within the framework of a sustainable environment.

The fabrication of constituent materials for FRP composites, namely matrix and fiber, are areas of concern especially when considering that the primary resources from which polymers (excluding biopolymers) are produced are crude oil, natural gas, chlorine, and nitrogen (Gerdeen et al. 2006). The most commonly used fiber reinforcements in structural applications, glass and carbon fibers, require high temperatures $\left(1,400^{\circ} \mathrm{C}\right.$ for glass; $1,200-2,400^{\circ} \mathrm{C}$ for carbon) during production and in some cases require petroleum by-products as precursors. When considering only energy and material resources it appears, on the surface, the

L. S. Lee · R. Jain $(\bowtie)$

School of Engineering and Computer Science, University

of the Pacific, Stocton, CA, USA

e-mail: rjain@pacific.edu argument for FRP composites in a sustainable, built environment is questionable. However, such a conclusion needs to be evaluated in terms of potential advantages present in use of FRP composites related to considerations such as:

- Higher strength

- Lighter weight

- Higher performance

- Longer lasting

- Rehabilitating existing structures and extending their life

- Seismic upgrades

- Defense systems unique requirements

- Space systems

- Ocean environments

\section{What is a sustainable material/environment?}

In order to evaluate the sustainability of FRP composites we must define a sustainable environment and how any material would comply within that definition. The sustainability concept, as described in the Common Future (World Commission on Environment and Development, 1987) states that:

Sustainable development is a process of change in which the exploitation of resources, the direction of investments, the orientation of technological development, and institutional change are all in harmony and enhance both current and future potential to meet human needs and aspirations. Sustainable development "...meets the needs of the present without compromising the ability of future generations to meet their own needs." 
Previously, the primary factors in materials selection for engineered systems were based on performance requirements and economics (e.g., construction and maintenance costs). The sustainability approach to design and construction challenges architects and engineers to weigh environmental factors, energy/resource consumption, social factors, economic considerations, and performance criteria. One approach toward evaluation of material sustainability involves life cycle assessment that includes the inputs and outputs for the phases of material life: raw materials acquisition, fabrication/processing, construction, maintenance, recycling/disposal.

When identifying appropriate metrics for sustainability, one is likely to encounter a myriad of proposals and ideas each potentially yielding unique results; however, in general, measures are typically centered on factors that account for the following:

1. Minimum resource use

2. Low environmental impact

3. Low human and environmental health risks

4. Sustainable site design strategies

5. Higher performance

The ideal sustainable structure and material would have a closed life cycle where renewable resources, energy, and zero waste, along with minimal impact on environment and society, are considered. Certainly, there are few materials that could qualify as ideal sustainable materials and still satisfy all the performance requirements of structural systems. Even more challenging are the demands of sustainable design which essentially seeks to achieve tailored design, construction, and maintenance plans depending on impact priorities, regional issues, and economic requirements.

In the case of FRP composites, environmental concerns appear to be a barrier to its feasibility as a sustainable material especially when considering fossil fuel depletion, air pollution, smog, and acidification associated with its production. In addition, the ability to recycle FRP composites is limited and, unlike steel and timber, structural components cannot easily be reused to perform a similar function in another structure. On the other hand, FRP composites' potential benefits, as described earlier, may potentially mitigate some environmental impacts.

It is important to note that the best way to minimize use of resources is to not rebuild in the first place. In this regard, the primary benefit of FRP composites will be its role in solutions that seek to extend the service life of existing structures and to develop new structures that achieve superior service life with minimal maintenance. Essentially, efficiently maximizing the benefit of potentially limited nonrenewable resources and avoiding the environmental, social, and economic impacts associated with replacement and new construction.

\section{Potential benefits and challenges}

The benefits of FRP composites can be realized from its physical characteristics and their potential in developing structural systems with service lives exceeding traditional materials. The light weight of the composite can result in lower construction costs and increased speed of construction resulting in reduced environmental impacts. FRP composite materials' high strength and stiffness characteristics can require less material to achieve similar performance as traditional materials resulting in minimizing resource use and waste production. In general, the promise of FRP composites is its potential to extend the service life of existing structures and to develop new structures that are far more resistant to the effects of aging, weathering, and degradation in severe environments.

However, validation of the durability of FRP composites in harsh, changing environments is not yet fully established. Quantification of durability of the material and its comparison to conventional materials is critical to provide designers with the knowledge to select the best solution toward achieving a sustainable, built environment.

While composite materials have many advantages, challenges in developing and implementing the technology exists. In addition to characterization of durability, innovations are needed in costs of production and minimizing environmental impacts. In terms of implementation, the development of codes and standards that include considerations for safety, performance, and sustainability are needed in transferring technology from laboratory to the market. Equally importantly, education of designers and architects is a paramount component of the use of composites in a built environment. Knowledge of the mechanical and hygrothermal behavior of FRP composites are as critical as the ability to conduct a life cycle analysis of choices made in the design stage. Published studies are necessary that compare the life cycle costs of a given structure under normal operating conditions. The service life extension needed from the use of FRP composites in order to offset any economic, social, and environmental concerns need to be quantified. The selection of FRP composites will depend on regional economic, socio-political, environmental, and performance factors and may not always provide the ideal solution; however, there is a need to objectively quantify the advantages and disadvantages of FRP composites as compared to other building materials. Questions that need to be addressed include: can the use of FRP composites for a new structure exceed the life of a structure constructed with conventional materials by two or three fold with improved performance?

As related to industrial practices in developing FRP composites, approaches will need to be developed, which focus on: 
- Reduce materials input, especially those natural resources with limited supplies.

- Reduce energy use in manufacturing.

- Replace or reduce hazardous or polluting material usage.

- Use lower polluting fuels and energy technologies for producing FRP composites.

- Recycle or use waste material for producing FRP composites.
- Produce upgradeable, longer lasting FRP composites.

- Minimize FRP composite life cycle environnemental impact.

\section{References}

Gerdeen JC, Lord HW, Rorrer RAL (2006) Engineering design with polymers and composites. CRC Press, Boca Raton 